\title{
PROPAGATING STRAIN ANOMALIES DURING MINI-SURGES OF VARIEGATED GLACIER, ALASKA, U.S.A.
}

\author{
By Charles F. RAYMOND and STEPHEN MALONE
}

(Geophysics Program AK-50, University of Washington, Seattle, Washington 98195, U.S.A.)

\begin{abstract}
Wire strain meters and seismometers spaced longitudinally along the upper part of Variegated Glacier, Alaska, showed quasi-periodic episodes of increased velocity (mini-surges), which lasted about 1 day and recurred at intervals of a few days to 2 weeks during the early part of the melt seasons of 1979, 1980, and 1981. The zone affected by these mini-surges corresponds to the zone of highest velocity and basal stress increase over the previous decade, and the initiation of the most recent surge in 1982 . Mini-surges initiate locally; as a single melt season progresses, the later mini-surges start at higher locations and show a distinct down-glacier propagation of a characteristic strain pattern and associated zone of acoustic emissions at speeds of $0.1-0.6 \mathrm{~km} \mathrm{~h}^{-1}$. During mini-surges, extensile and compressive strain-rates exceed $10 \times 10^{-4} \mathrm{~d}^{-1}$ and $40 \times 10^{-4} \mathrm{~d}^{-1}$, respectively; typical strain-rates between mini-surges were less than $2 \times 10^{-4} \mathrm{~d}^{-1}$ in magnitude. Seismic activity jumped by two orders of magnitude and was distinctly audible during a mini-surge. Maximum strainrate during mini-surges decreased from year to year. The high time resolution of the strain allows short time-scale structure of velocity variations to be deduced. As a propagating mini-surge passes, the velocity anomaly at a fixed location is characterized by a rapid initial rise over a few hours to two distinct peaks separated by a few hours, followed by a slower return to normal velocity taking up to a day. The double peak in velocity may arise from a single, very sharp, transient peak in the basal slip velocity associated with the initial opening of cavities at the base in response to a sudden rise in basal water pressure (observed by Kamb and Engelhardt). This supports an important role for basal cavitation in the mini-surge mechanism.
\end{abstract}

RÉsumÉ. Propagation d'anomalies de déformation au cours de mini-surges sur le Variegated Glacier, Alaska, U.S.A. Des jauges de déformation et des géophones disposées longitudinalement sur la partie supérieure du Variegated Glacier, Alaska, ont montré des épisodes quasipériodiques des déplacements accélérés (mini-surge), qui duraient environ 1 jour et se reproduisaient à intervalles de quelques jours à 2 semaines au cours du début de la saison de fonte des années 1979, 1980 et 1981. Les zones affectées par ces mini-surges correspondent à la zone de plus forte vitesse et d'augmentation de contrainte basale lors de la décade antérieure et du début de la plus récente surge en 1982. Les mini-surges débutent localement; avec la progression de la saison de fonte d'autres mini-surges se développent dans les zones supérieures et montrent une propagation à l'aval distincte par leurs caractéristiques de déformation et leur zones associées d'émissions acoustiques à la vitesse de 0,1 à $0,6 \mathrm{~km}$ par heure. Pendant les minisurges des taux de déformation extensifs ou compressifs on dépassé $10 \times 10^{-4} \mathrm{~d}^{-1}$ et $40 \times 10^{-4} \mathrm{~d}^{-1}$ respectivement; les taux de déformations habituels entre les mini-surges étaient inférieurs à $2 \times 10^{-4} \mathrm{~d}^{-1}$. L'activité sismique s'éleva de deux ordres de grandeur et fut audible pendant une mini-surge. Les taux de deformation pendant les mini-surges décroissent d'année en année. La haute résolution temporelle de la déformation permet d'en déduire une structure de variation de la vitesse sur de courts espaces de temps. Au passage de la mini-surge, l'anomalie de vitesse en site fixe est caractérisée par une augmentation initiale rapide sur quelques heures avec deux pics séparées de quelques heures, suivis par un plus lent retour à la normale sur plus d'un jour. Le double pic de vitesse peut être créé par un seul, très intense pic dans la vitesse de glissement basal associé au début d'ouverture des cavités sur le lit en réponse à une augmentation brusque de la pression d'eau (observation de Kamb et Engelhardt). Cela milite en faveur du rôle important joué par les cavités basales dans le mécanisme des mini-surges.

ZUSAMMENFASSUNG. Fortpflanzung von Spannungsanomalien während Klein-Ausbrüchen des Variegated Glacier, Alaska, U.S.A. Draht-Spannungsmesser und Seismometer, ausgelegt in der Längsachse des oberen Variegated Glacier, Alaska, zeigten quasi-periodisches Auftreten von erhöhter Geschwindigkeit (Klein-Ausbrüche) an, das etwa einen Tag lang anhielt und in Intervallen von einigen Tagen bis zu zwei Wochen zu Beginn der Schmelzperioden von 1979, 1980 und 1981 wiederkehrte. Die von diesen Klein-Ausbrüchen betroffene Zone fält mit der Zone höchster Geschwindigkeit und Zunahme der Spannung am Untergrund wăhrend des letzten Jahrzehnts und dem Ausgangsgebiet des jüngsten Ausbruches im Jahre 1982 zusammen. Klein-Ausbrüche beginnen lokal - im Verlauf einer einzelnen Schmelzperiode wandern die Klein-Ausbrüche gletscheraufwărts und zeigen verschiedene Fortpflanzung gletscherabwărts mit charakteristischen Spannungsmustern und damit verbundene Zonen akustischer Emission mit Geschwindigkeiten von $0,1-0,6 \mathrm{~km} / \mathrm{h}$. Während der KleinAusbrüche überschreiten Zug- und Druckspannungsraten die Werte $10 \times 10^{-4} \mathrm{~d}^{-1}$ bzw. $40 \times 10^{-4} \mathrm{~d}^{-1}$; typische Spannungsraten zwischen Klein-Ausbrüchen waren kleiner als $2 \times 10^{-4} \mathrm{~d}^{-1}$. Während eines Klein-Ausbruches wuchs die seismische Aktivităt sprunghaft um zwei Grössenordnungen und war deutlich hőrbar. Die maximale Spannungsrate wăhrend der Klein-Ausbrüche nahm von Jahr zu Jahr ab. Die hohe zeitliche Auflösung der Spannung erlaubt die Herleitung einer kurzzeitigen Struktur der Geschwindigkeitsschwankungen. Wenn ein Klein-Ausbruch durchlăuft, ist die Geschwindigkeitsanomalie an einer bestimmten Stelle durch eine schnelle anfängliche Zunahme innerhalb weniger Stunden und zwei deutliche Höhepunkte, zwischen denen einige Stunden liegen, gekennzeichnet - dann folgt im Zeitraum bis zu einem Tag eine langsame Rückkehr zu normalen Geschwindigkeiten. Das doppelte Geschwindigkeitsmaximum dürfte von einem einzelnen, sehr scharfen vorübergehenden Maximum in der Gleitgeschwindigkeit am Untergrund verursacht sein, verbunden mit dem Aufbruch von Hohlräumen am Untergrund als Auswirkung einer plötzlichen Zunahme des Wasserdrucks (beobachtet von Kamb und Engelhardt). Dies ist eine Stütze für die Annahme einer wichtigen Rolle von Hohlrăumen am Untergrund im Mechanismus der Klein-Ausbrüche. 


\section{INTRODUCTION}

Variations in velocity on the time-scale of weeks or less have been observed on many glaciers. They are usually explained by water-induced, basal-sliding variations and their study provides an opportunity to examine how water affects basal sliding. Closely spaced measurements of velocity versus time have provided some detailed information about temporal variation at a fixed location (e.g. Flotron, 1973; Iken, 1978; Iken and others, 1983). There is little information about how such velocity variations evolve in space. Do they affect a large length of a glacier simultaneously? Do they start locally and spread out? Or do they propagate down-glacier?

We address these questions using strain measurements on Variegated Glacier during the early part of the melt seasons of 1979, 1980, and 1981. Variegated Glacier surged in 1982 (Kamb and others, 1985), and the observations also provide information about the glacier's behavior just prior to surge initiation. Strain was measured at various longitudinal positions along the glacier directly using continuousrecording, wire strain meters, and indirectly using seismic recording of acoustic emissions. The primary motivation was to search for longitudinally propagating strain anomalies, and thereby remotely sense propagation of basal sliding-rate anomalies and the speed of hydraulic waves in the basal water drainage system.

Quasi-periodic occurrence of propagating strain anomalies was observed and this, together with other extensive observations by our colleagues, led to the discovery of mini-surges of Variegated Glacier. Direct observation of velocity variations, uplift of the surface, and basal water pressure are given by Kamb and Engelhardt (in press). Here we are concerned with accurate determination of time variation and propagation speeds afforded by the precision and time resolution of the continuous-recording strain meters and an assessment of seismic monitoring for sensing mini-surge occurrence. Humphrey and others (1986) discuss changes in stage and water turbidity in the principal terminal stream, which they interpret to find estimates of mean water velocity and water-flow cross-sections in the basal drainage system.

\section{DESCRIPTION OF VARIEGATED GLACIER AND MEASUREMENT SITES}

Figure 1 shows a map of Variegated Glacier. Position on the glacier is referenced by distance from the head of the glacier and distance to the right or left of the center line; kilometer positions are shown by ticks.

The geometry and dynamic characteristics of the glacier in 1973 and 1974 have been described by Bindschadler and others (1977). The history of past major surges indicates they occur about every 20 years. The most recent surges occurred in 1964-65, and in 1982-83. From 1973 to 1981, there were progressive changes in geometry and speed, with the largest increases in surface speed and inferred sliding speed occurring in the reach from about 3 to $9 \mathrm{~km}$ (paper in preparation by C.F. Raymond and W.D. Harrison). It is in this zone that mini-surge activity has been documented and the 1982 surge was initiated. A tributary enters the main glacier in this reach (Fig. 1) and may play a role in its dynamics.

This discussion is restricted to the 3 to $9 \mathrm{~km}$ zone and the early part of the melt season (June and July). Harrison and others (1986) used time-lapse photographic measurement of daily glacier speed and seismic activity to show the existence of significant but smaller-speed variations at other times and locations.

\section{METHODS}

\section{Strain meters}

The wire strain meters were similar in design to others commonly used in geophysics and recently employed on glaciers (e.g. Evans and others, 1978). Because strain-rates were very large (up to $5 \times 10^{-3} \mathrm{~d}^{-1}$ ), high sensitivity was not needed and a fairly crude mechanical and electrical design was adequate. The principal difficulty was achieving a secure attachment to the glacier during summer melting conditions.

The change in distance between two piers $(0.075 \mathrm{~m}$ outside diameter, $2.2 \mathrm{~m}$ length) anchored in the glacier $(10 \mathrm{~m}$ apart) was sensed by the motion of a wire (invar $0.25 \mathrm{~mm}$ diameter) fixed at one pier, and held at constant tension $(2.8 \mathrm{~N})$ by a pivoted balance and weight $(0.3 \mathrm{~kg})$ at the other. The motion of the wire was sensed by a LVDT $(12-24 \mathrm{~V}$ d.c. input, $0.6 \mathrm{~V} / \mathrm{mm}$ displacement sensitivity) which sensed the motion of the balance with an adjustable mechanical amplification of $1 / 3$ to 3 . The transducer signal was recorded on a chart recorder $( \pm 1.5 \mathrm{~V})$ with a $12 \mathrm{~V}$ d.c. regulated motor drive. With the mechanical amplification of 3 and the $10 \mathrm{~m}$ base line, the strain resolution was $10^{-6}$. A total displacement of $3 \mathrm{~mm}$ or strain of $3 \times 10^{-4}$ could be sensed. If this was exceeded, wire had to be pulled in or out to bring the signal back on scale. In 1979, this was done manually. In 1980 and 1981, this was done automatically by a linear stepping motor activated by a voltage comparator when the transducer signal went outside pre-set lower and upper bounds.

In order to isolate meters from melting and wind, they were installed in trenches initially $1-2 \frac{1}{2} \mathrm{~m}$ deep. The invar wire was run through $10 \mathrm{~m}$ of $0.1 \mathrm{~m}$ i.d. plastic pipe, supported by posts and by snow packed around it. This insured a wire temperature held nearly constant at meltingsnow temperature. To achieve a secure pier installation, each pier was put in a hole drive-cored by itself, which gave an initially tight fit. Immediately after installation, snow-salt mixtures in canisters were lowered into the pier to freeze it in. In 1979 and 1981, the ends of the meter were covered

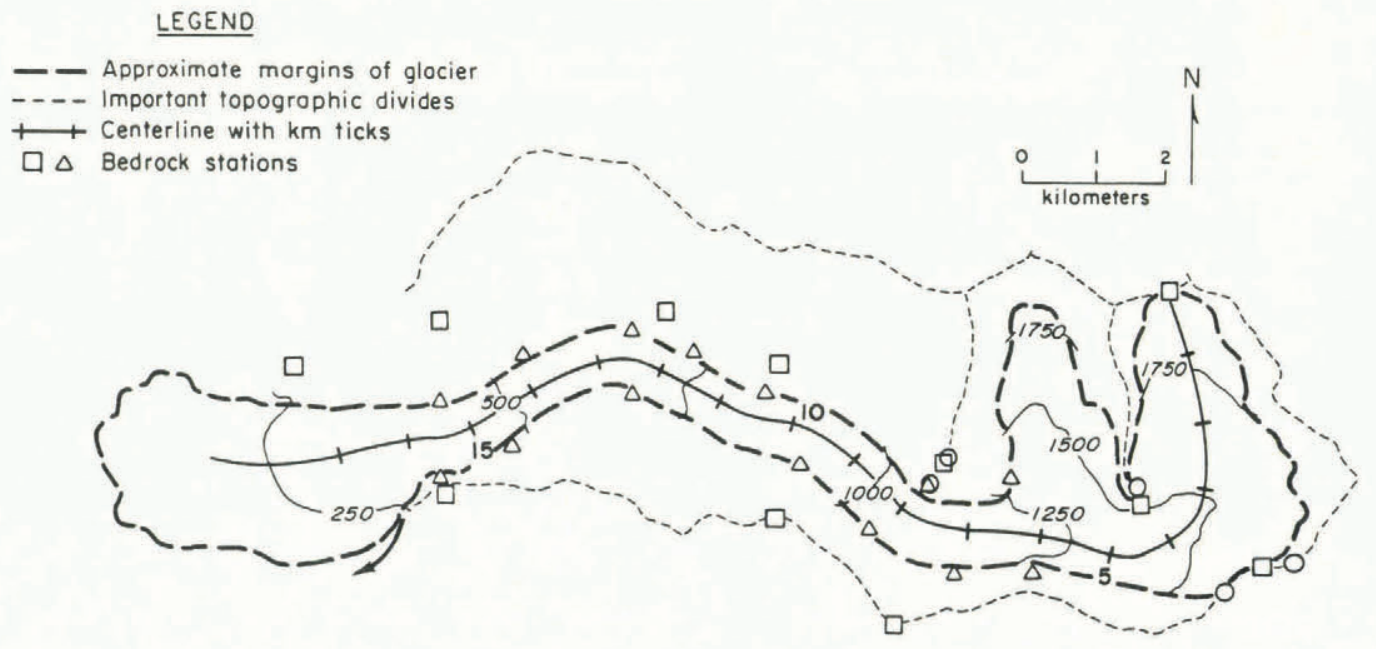

Fig. 1. Map of Variegated Glacier with ticks showing integral kilometer positions measured from the head of the glacier. 


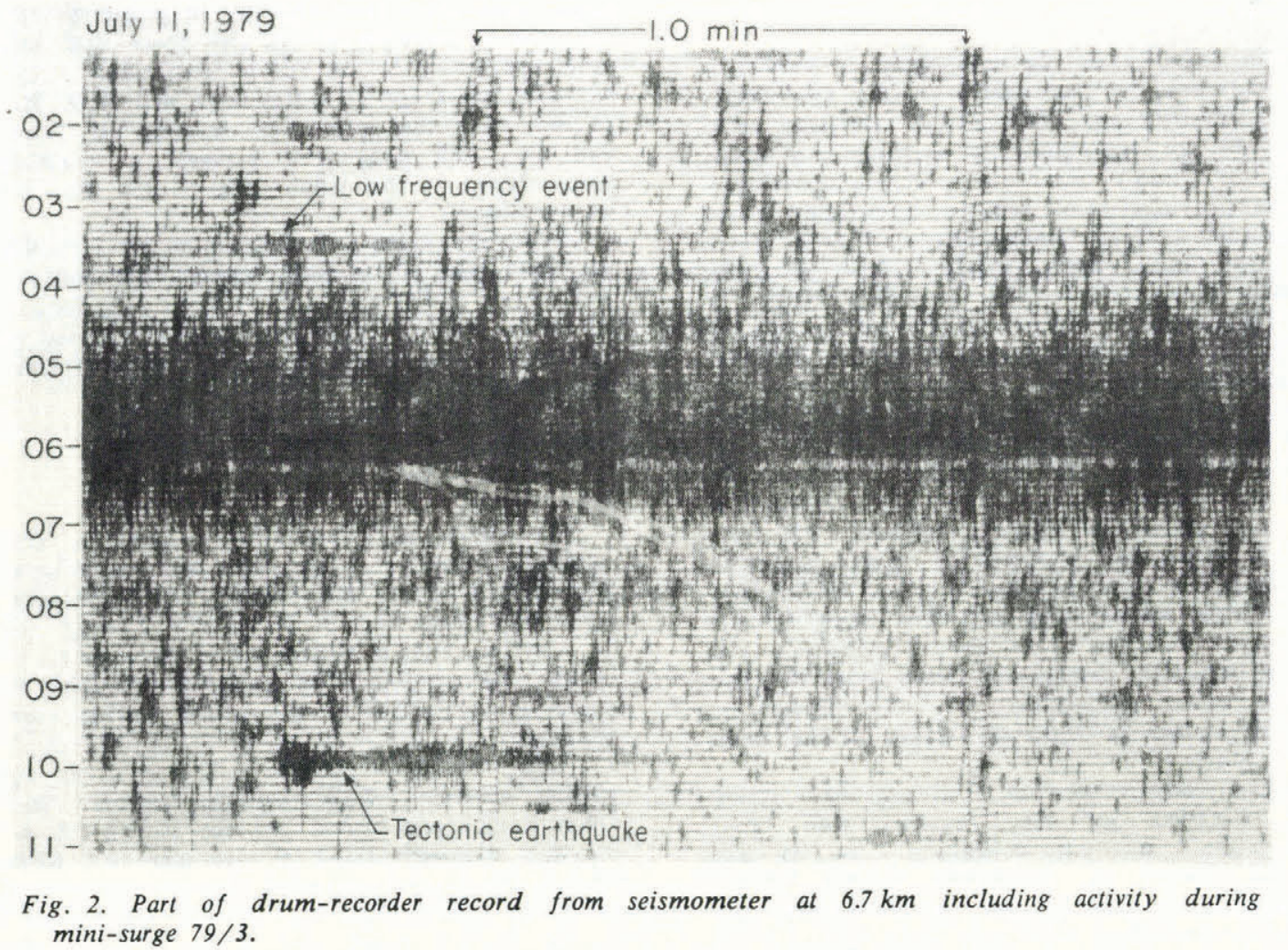

with plywood sheets and buried, except for small access passages. Under these conditions, piers remained tight and meters functioned well for 1 week to 1 month, depending on initial burial depth and weather. Because of the large number of installations in 1980, meters were not installed as deeply and the ends were not buried as in 1979 and 1981. This worked adequately most of the time, but various melting-induced problems were frequent, with resulting loss of data.

The relationship between local strain-rate measured by wire meters to a regional strain-rate measured by surveying is examined in Table I. In each case, the tabulated strain- rate represents an average over a multi-week interval. In view of the differences in time intervals and the uncertainties in the regional scale strain-rate estimates, the agreement between the local and regional scales was quite good in 1979 and 1981. In 1980, wire strain-meter results are distinctly more compressive than the corresponding regional scale strains by up to $4 \times 10^{-4} \mathrm{~d}^{-1}$. This is apparently an instrumental effect associated with the different installation and also much warmer weather in 1980 compared to 1979 and 1981. It is caused by melting and consequent tilting of the piers. The spurious signal is biased toward compression, as a result of the piers tilting toward one another under the

TABLE I. SECULAR STRAIN-RATES $\left(10^{-4} \mathrm{~d}^{-1}\right)$

Location
$\mathrm{km}$ from
head

\author{
Full summer average \\ (approx. 20 June \\ to 1 September)
}

(from survey of glacier markers (approx. $0.25 \mathrm{~km}$ apart)

\section{1 month average (approx. 20 June to 20 July)}

(from strain meter (10 $\mathrm{m}$ base line $)$ )
Based on smoothing by optimal interpolation
Based on differences of adjacent markers

1979

5.5

6.7

7.5

1980

4.3

5.5

7.0

8.3

9.6

Tributary

1981
-0.9
-
-1.9

$+0.8$

$-1.1$

$-1.6$

$-1.4$

$+0.3$
$-1.1$

0.0

$-1.6$

$+1.4$

$-1.5$

$-2.0$

$-1.3$

$-0.2$ 
influence of wire tension and off-center mounting of the strain-meter components. This bias could be alleviated by a better mechanical design to balance the wire tension and gravitational torques, but the limitations imposed by melting would remain.

Based on the experiences of the three years, it is difficult to measure long-term strain with these wire meters in temperate conditions. They work well for sensing short time-scale strain events, in which strain-rate anomalies are larger than several times $10^{-4} \mathrm{~d}^{-1}$.

\section{Seismographs}

In June and July of 1979, a single-channel, ink-pen drum recorder with a $1.0 \mathrm{~Hz}$ seismometer was operated on the glacier surface $6.7 \mathrm{~km}$ from its head. At wide-band filter settings this instrument recorded a variety of seismic events. Most can be classified into one of three types: (1) tectonic earthquakes which occur at some distance from the glacier and have a signal character similar to earthquakes recorded off the glacier; (2) low-frequency events with a monochromatic character and no obvious body-wave phases, which are similar to those described by VanWormer and Berg (1973) and Rogers (unpublished); (3) high-frequency, short-duration events (Fig. 2). The type (3) events showed dramatic variations in occurrence rate correlated with changes in glacier motion and were presumably caused by surface cracking.

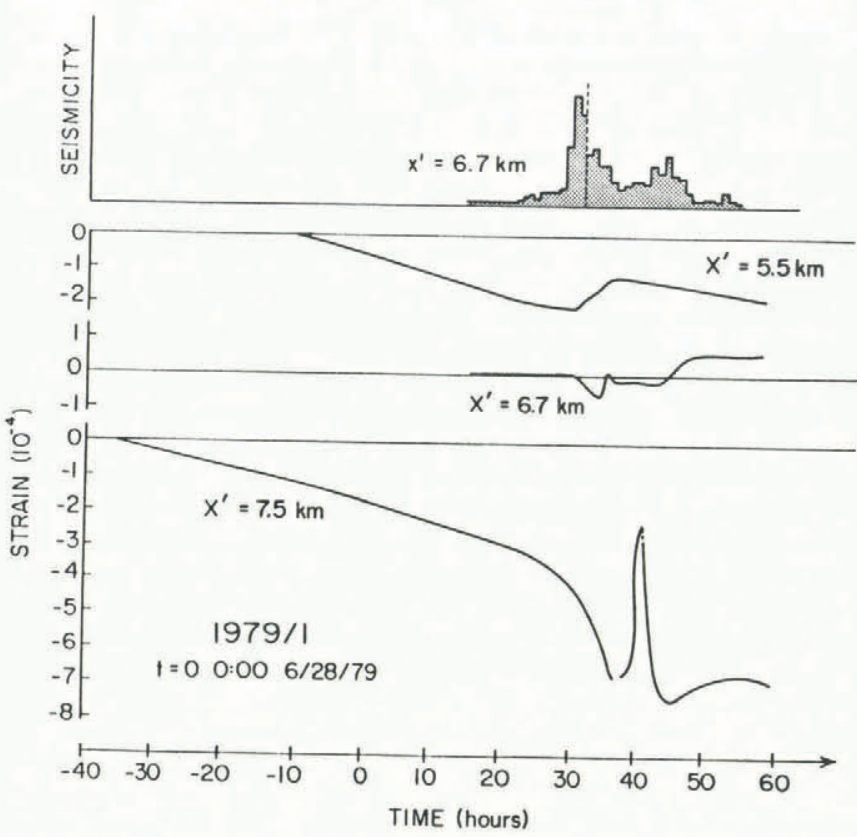

Fig. 3. Strain and seismicity records for mini-surge $79 / 1$. (Vertical dashed line on seismicity record shows time of gain adjustment in the recorder amplifier. Subsequent data are re-normalized to account approximately for the change in instrument characteristics.)

In order to monitor seismic activity in a simplified way, inexpensive event counters were designed and constructed. These instruments use a $4.5 \mathrm{~Hz}$ geophone, eventdetection electronics, and a pulse counter. The pulse counter is a commercially available traffic counter whose input is a voltage pulse. It counts the number of pulses during a specified interval of time and records this number by both punching and printing on paper tape. Pulses are generated by the event-detection electronics which amplifies, band-pass filters $(10-50 \mathrm{~Hz})$, rectifies, and integrates the geophone signal. The integrated signal is high-pass filtered above $1 \mathrm{~Hz}$ and then compared to an adjustable reference voltage. When this voltage is exceeded, a trigger pulse is sent to the counter. An inhibit timer prevents initiation of another pulse until a certain time has elapsed. This prevents a later part of a single event from causing more than one pulse. The design of the detection electronics produces low sensitivity to detection of low-frequency (type (2)) events and therefore selects the type (3) events of principal interest

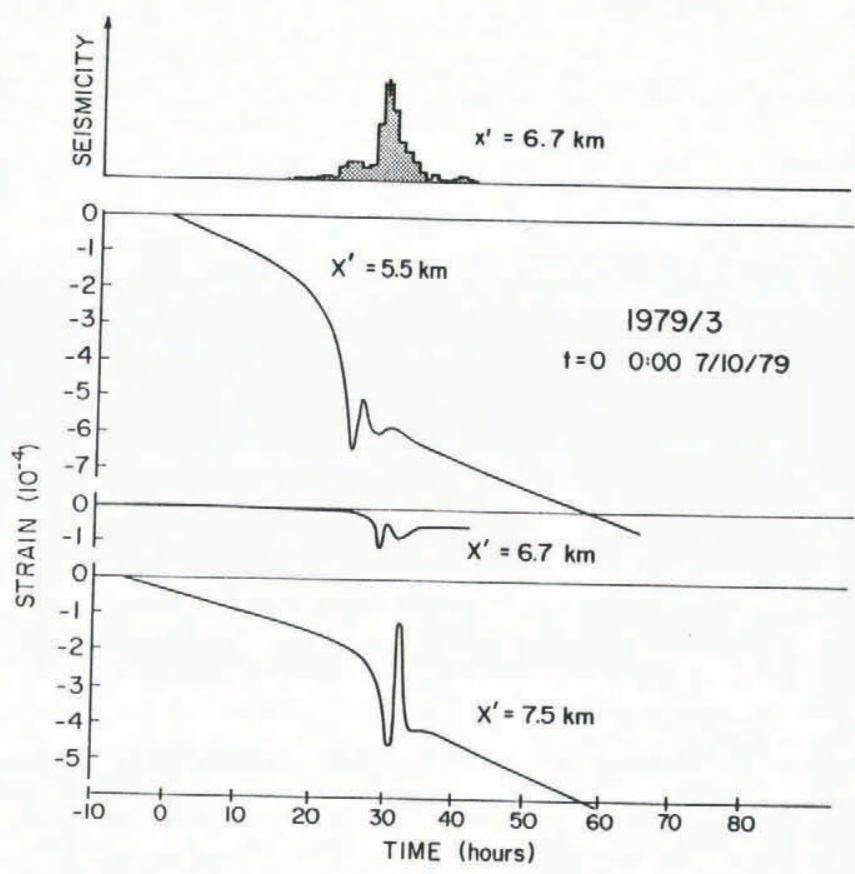

Fig. 4. Strain and seismicity records for mini-surge $79 / 3$.

here. Since the typical type (3) event lasts only 1 or $2 \mathrm{~s}$, the inhibit timer was set to $3 \mathrm{~s}$. After some initial problems with temperature stability and a faulty recorder, these event counters worked very well. They were deployed extensively in 1980 and 1981, and were left unattended for many months to obtain data through parts of the winter (Harrison and others, 1986). A comparison of the count records generated by the event counters and those produced by counting events by hand from a drum record such as Figure 2 showed good agreement between the two methods.

\section{STRAIN DURING MINI-SURGES}

\section{Recognition of mini-surges}

Mini-surges are easily recognized as brief episodes of anomalous straining and high seismic activity in contrast to extended periods of relatively constant strain-rate and low seismic activity. These events in strain and seismic activity

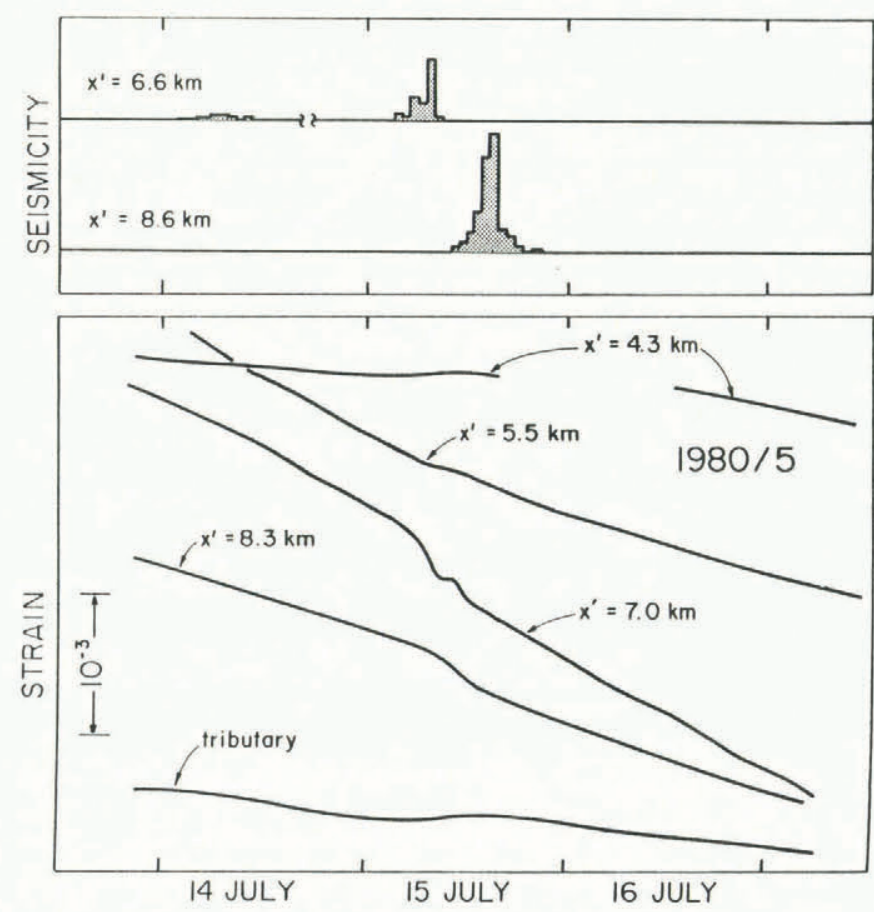

Fig. 5. Strain and seismicity records for mini-surge $80 / 5$. 
coincide with episodes of faster glacier speed, as discerned by daily surveying and photography (Harrison and others, 1986) and shorter time-scale surveying (Kamb and Engelhardt, in press). We shall be concerned with the details of behavior during mini-surges. Figure 2 illustrates the dramatic change in seismic activity during a mini-surge. Figures 3 through 6 give detailed examples of strain which show various features of the strain patterns and their relation to seismicity.

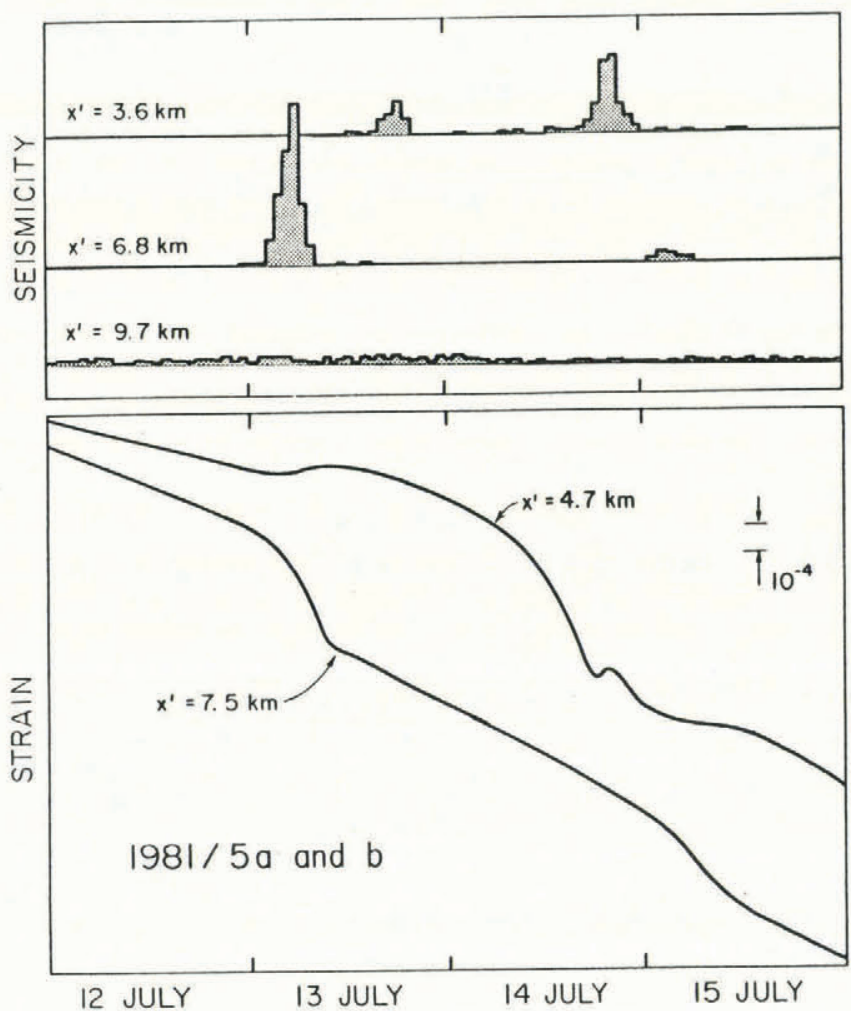

Fig. 6. Strain and seismicity records for mini-surge $81 / 5 a$ and $5 b$.

\section{Definition of strain-rate and strain anomaly}

The surface-parallel speed of the glacier surface may be described as

$$
\dot{U}(x, t)=\dot{U}_{\mathrm{s}}(x)+\dot{u}(x, t)
$$

where $\dot{U}_{S}(x)$ represents the secular speed variation with distance $x$ along the length of the glacier and $\dot{u}(x, t)$ represents a time-dependent velocity anomaly. The longitudinal strainrate is

$$
\dot{E}(x, t)=\frac{\partial \dot{U}(x, t)}{\partial x}=\dot{E}_{\mathrm{s}}(x)+\dot{e}(x, t)
$$

where $\dot{E}_{\mathrm{s}}(x)=\mathrm{d} \dot{U}_{\mathrm{s}}(x) / \mathrm{d} x$ is the secular strain-rate and $\dot{e}(x, t)=\partial \dot{u}(x, t) / \partial x$ is the strain-rate anomaly. If $t=0$ is chosen at a given location $x$ as the time that anomalous straining starts during a mini-surge, an accumulated strain anomaly can be defined as

$$
e(x, t)=\int_{0}^{t} \dot{e}(x, \tau) \mathrm{d} \tau .
$$

Likewise, an accumulated displacement anomaly can be defined as

$$
u(x, t)=\int_{0}^{t} \dot{u}(x, \tau) \mathrm{d} \tau .
$$

Time variation of strain at fixed location

Strain versus time could take several forms. The double-wave pattern during mini-surge $80 / 5$ at $7.0 \mathrm{~km}$ (Fig. 5) is characteristic. It is started by a transition to an increased compression rate, and this is followed by subsequent transitions to relative extension, compression, extension, and ultimately compression, to end anomalous straining. This double-wave pattern was most dramatically displayed during the mini-surges of 1979 (Figs 3 and 4). Somewhat simpler patterns were also seen; for example, single periods of anomalous relative extension (Fig. 3; 79/1 at $5.5 \mathrm{~km}$ ) and compression (Fig. 6; 81/5a at $7.5 \mathrm{~km}$ ) were seen. Total strain anomaly during the course of a mini-surge could be compressive (Fig. $4 ; 79 / 3$ at $5.5 \mathrm{~km}$ ) or extensile (Fig. 3; 79/1 at $5.5 \mathrm{~km}$ ).

Table II gives information about peak strain-rate $(\dot{e})$, strain $(e)$, and total accumulated strain anomaly $\left(e_{\text {total }}\right)$ for each mini-surge and measurement location, based on the definitions of Equations (2) and (3). For reference, the secular strain-rate $\left(\dot{E}_{\mathrm{S}}\right)$ determined over several days before the mini-surge is also given.

The listed peaks in $\dot{e}$ are the absolute maximum and minimum values in the course of a mini-surge. Strain-rate was calculated by differencing strain values at $0.16 \mathrm{~h}$ intervals. For this purpose, the digitized strain records were first smoothed by twice applying a 9 point digital filter to reduce digitization error and high-frequency noise in the record. Further elimination of high-frequency variations was achieved by twice applying the same filter to the derived strain-rate record. As a result, the computed strain-rate represents averages over a time interval longer than the $0.16 \mathrm{~h}$ differencing interval, and $\dot{e}$ may have larger, unresolved short-term excursions than tabulated.

The listed peaks in $e$ are the first minimum $e)_{\min 1}$ and the first maximum $e$ ) . When there are no peaks, then either $e)_{\max 1}$ or $\left.e\right)_{\min 1}$ is the same as $\left.e\right)_{\text {total }}$ and the other is listed as zero (depending on whether there was anomalous extension or compression). A distinct double-wave pattern is recognized by definite differences between all three quantities $\left.e)_{\min 1}, e\right)_{\max 1}$, and $\left.e\right)_{\text {total }}$.

Transitions to relative extension or compression identify characteristic points in the strain anomaly patterns. These transitions are defined by the condition $\dot{e}(x, t)=0$. The timing of such transitions for operating strain meters during

Explanation - Table II.

$\dot{E}_{s}$ is the strain-rate before anomalous straining starts.

$\dot{e})_{\min }$ and $\left.\dot{e}\right)_{\max }$ are measured from peaks in strain-rate calculated from 9 point smoothing of strain-rate applied twice, differentiation, and 9 point smoothing of resulting strain-rate applied twice.

$e)_{\min }$ is value for first minimum.

e) $)_{\max }$ is value for first maximum.

If there is no extension phase, $\left.e)_{\min }=e\right)_{\text {total }}$ and $\left.e\right)_{\max 1}=0$.

If there is no compression phase, $e)_{\min 1}=0$ and $\left.\left.e\right)_{\max 1}=e\right)_{\text {total }}$ 
TABLE II. STRAIN-ANOMALY PARAMETERS

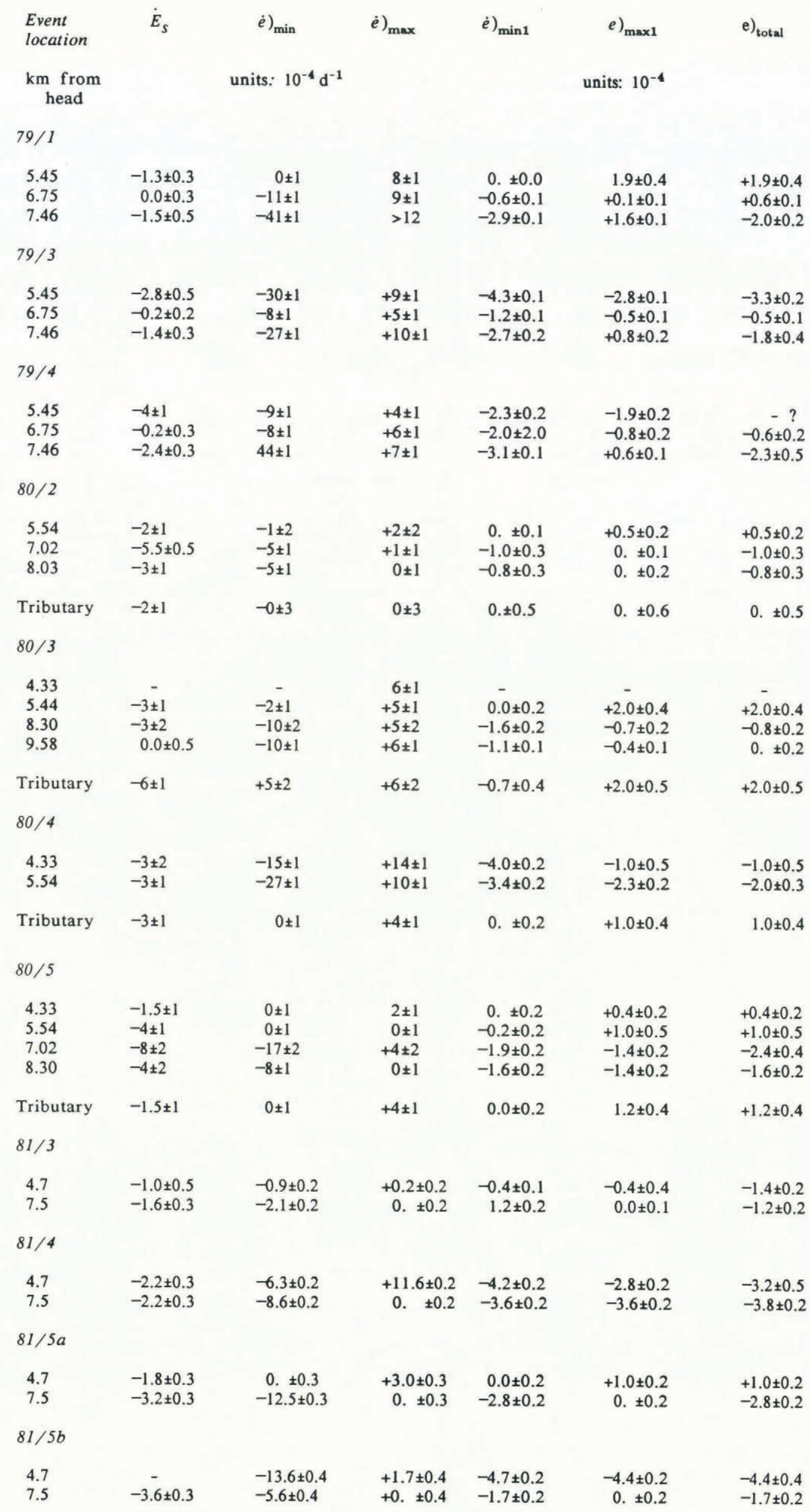



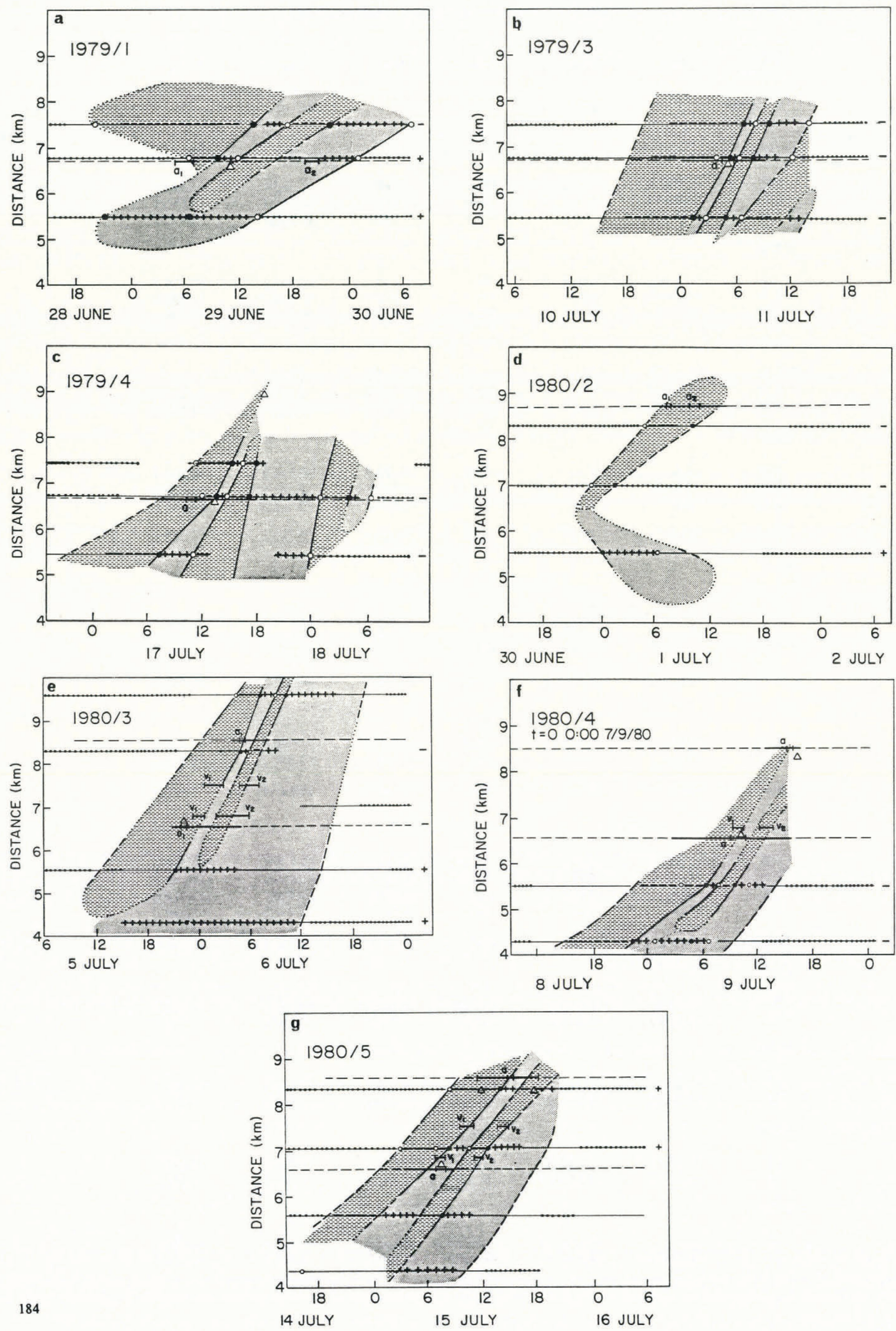

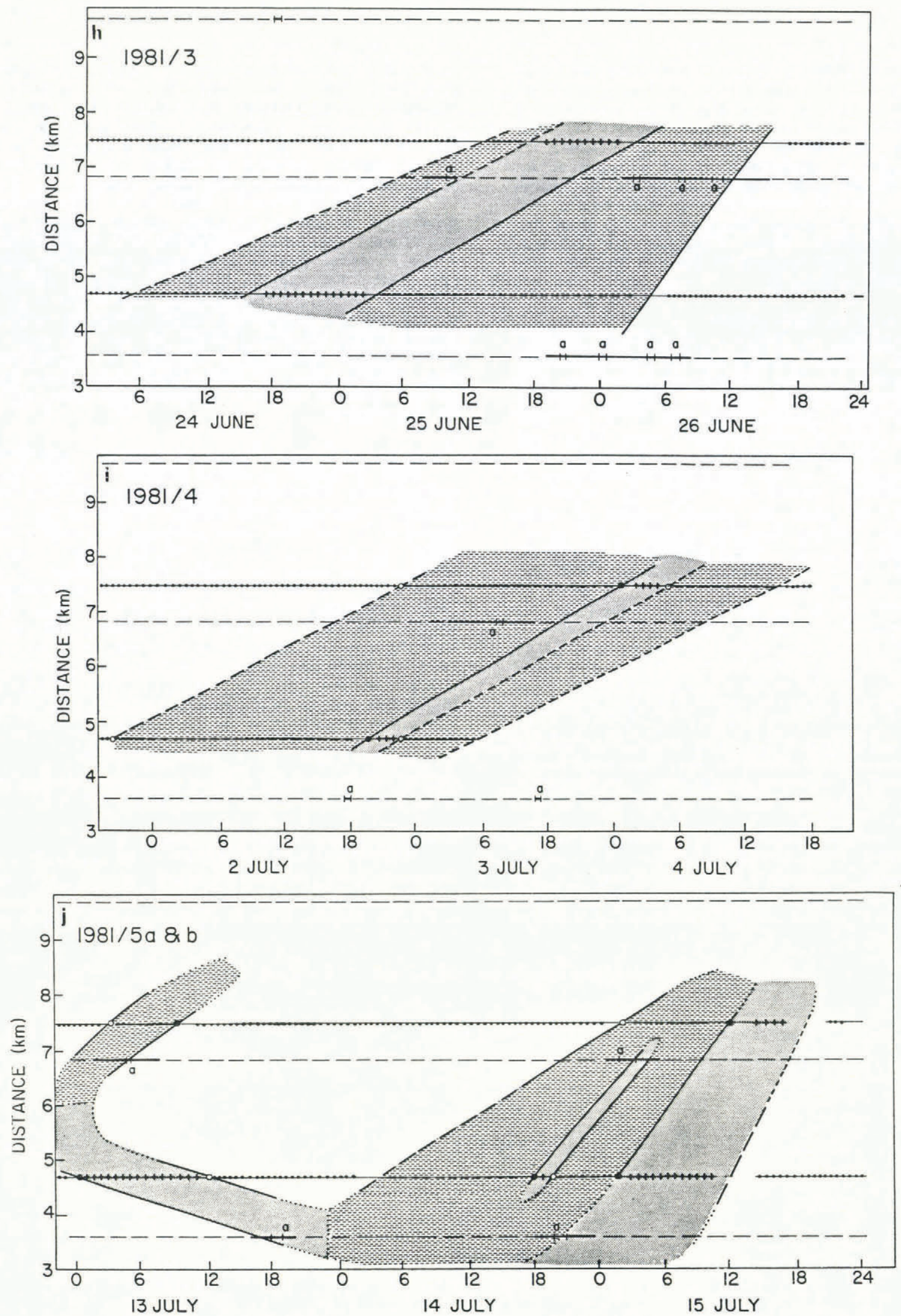

Fig. 7. Propagation diagram for mini-surges. Horizontal solid lines indicate the longitudinal position of strain meters (gaps in the line indicate times when a meter was not working). Affixed symbols indicate whether the strain-rate anomaly is extensile (+++), compressive (---), or near zero (......). Gaps in the progression of symbols indicate transitions between those that are gradual and cannot be timed better than the interval of the gap. Circle data points show the times of distinct changes in strain-rate with solid points indicating increased relative extension rate and open points indicating increased relative compression rate. Diagonal lines join correlated strain-rate transitions at different locations and times where - indicates a large change in strain-rate $\left(\left|\Delta \dot{e}^{*}\right|>5 \times 10^{-4}\right)$ localized in time $(\Delta t<0.3 \mathrm{~h}),--1$ indicates a large change but spread out in time, - - - indicates a weak change in strain-rate, and .... indicates inference by extrapolation. Shading indicates space-time zones of anomalous extension (*) and compression . Horizontal dashed lines show positions and periods of operation of recording seismometers. The superimposed heavy lines indicate times of heightened seismic activity and the vertical bars labeled " $a$ " bracket the hour of highest activity. Bars labeled " $v$ " indicate velocity peaks and $\Delta$ indicate water-level peaks measured by Kamb and Engelhardt (in press). 
each mini-surge is shown in Figure 7. Sometimes the timing is sharply defined within the $0.16 \mathrm{~h}$ sampling interval and can be indicated as a point in time at the resolution of Figure 7. Other transitions are more gradual and their timing cannot be specified precisely, as indicated by symbols in Figure 7. Independent of the accuracy of the timing, there are also differences in the size of the change in strain-rate, which is sometimes large and obvious, and other times barely perceptible above instrumental noise and other natural variations. These differences are conveyed qualitatively by different symbols in Figure 7 and expressed by error estimates in Table II.

\section{Spatial evolution of the strain pattern}

Strain anomalies at different longitudinal positions usually showed correlation with a time lag indicating downglacier propagation. A clear example is mini-surge $79 / 3$ where a qualitatively similar anomaly pattern occurred at the three longitudinally separated sites (Fig. 4). In this case, the mini-surge seems to have originated above $5.5 \mathrm{~km}$ and propagated to below $7.5 \mathrm{~km}$. This indicates the double-wave pattern is characteristic of the passage of a mini-surge. A somewhat different interpretation must be given to mini-surge $79 / 1$ for which the straining pattern at $5.5 \mathrm{~km}$ was qualitatively different than for the lower sites at 6.7 and $7.5 \mathrm{~km}$ (Fig. 3). A reasonable interpretation is that the mini-surge started below $5.5 \mathrm{~km}$ or entered from the tributary (Fig. 1), causing extension of the ice above its starting or entry location. In this case, the mini-surge also apparently propagated to below $7.5 \mathrm{~km}$. The records for 1980 and 1981 show cases where mini-surge propagation stopped above the lower strain meters, resulting in a single compression (e.g. Fig. 6). From these considerations, it is possible, in a number of cases, to bracket where mini-surge propagation is initiated and dies out. The propagation of the strain pattern can be seen in Figure 7, where strain features at different positions are joined by lines. The lines outline space-time zones of anomalous compression and extension. The slopes of the lines give longitudinal propagation speed of strain-pattern features.

The most well-defined feature of the strain patterns is the first transition from relative compression to extension. Table III catalogs the average velocity inferred for this feature (over various distance intervals for different minisurges) when it is present. Propagation speed is different from one mini-surge to another with no apparent systematic progression with time. There is some indication that propagation speed increases down-glacier. Also, when there is a well-defined, sub-parallel propagation of similar features of the anomaly pattern, there is a possible tendency for convergence, indicated by slightly shorter time intervals of anomalous straining at lower meter sites.

For some mini-surges, there is no clear pattern of propagation evident in the strain anomaly patterns sampled at the meter sites. This is expected if a propagating strain anomaly initiates between strain-meter sites, but it also may arise from other patterns of velocity anomaly that do not propagate. In these cases, the space-time evolution of areas of extension and compression cannot be defined well by the limited spatial sampling afforded by the few meter sites. The boundaries indicated in Figure 7 are correspondingly more uncertain than for cases where similar strain anomaly patterns displaced in space and time give some confidence for interpolation.

\section{Correlation of seismic activity with strain-rate anomalies}

Since the peaks in seismic activity are short $(\approx 1 \mathrm{~h})$ in comparison to the time of anomalous straining, it is possible to seek a correlation with specific features of the anomaly pattern (Fig. 7). There is a tendency for seismic activity peaks to occur close to transitions from anomalous compression to extension. Within the time resolution of the strain meter and the counting interval of the seismometer there is sometimes a perfect coincidence, but frequently the seismic peak can be displaced by several hours. In some cases there is no apparent correlation of seismic peaks with extension, unless the noise source is in a zone of extension remote from the measurement site. Nevertheless, the seismic information can be used (with caution) to interpolate and extrapolate propagation of the strain-rate anomaly pattern.

\section{INTERPRETATION OF STRAIN-RATE ANOMALIES IN TERMS OF VELOCITY VARIATIONS}

\section{Qualitative pattern of velocity variation}

Figure 8 shows idealized patterns of strain-rate anomaly associated with certain simplified patterns of velocity anomaly. These include rigidly moving blocks or zones, and peaks that may be fixed in space, spreading or propagating.

TABLE III. PROPAGATION SPEED OF PRINCIPAL EXTENSION TRANSITION

$\begin{array}{ccc}\text { Year/mini-surge } & \begin{array}{c}\text { Distance interval } \\ \mathrm{km}\end{array} & \begin{array}{c}\text { Speed } \\ \mathrm{km} \mathrm{h}^{-1}\end{array} \\ 1979 / 1 & 5.45-6.75 & 0.10^{\dagger} \\ & 6.75-7.46 & 0.20 \pm 0.06 \\ 1979 / 3 & 5.45-6.75 & 0.33 \pm 0.03 \\ & 6.75-7.46 & 0.39 \pm 0.09 \\ 1979 / 4 & 5.45-6.75 & 0.21 \pm 0.01 \\ & 6.75-7.46 & 0.51 \pm 0.11 \\ 1980 / 3 & 5.54-8.30 & 0.37 \pm 0.03 \\ & 8.30-9.58 & 0.59 \pm 0.05 \\ 1980 / 4 & 4.3-5.5 & 0.15 \pm 0.00 \\ 1980 / 5 & 5.5-8.6 & 0.31 * \\ 1981 / 3 & 5.5-7.0 & 0.19 \pm 0.01 \\ 1981 / 4 & 7.0-8.3 & 0.22 \pm 0.01 \\ 1981 / 5 \mathrm{~b} & 4.7-7.5 & 0.11 \pm 0.01 \\ & 4.7-7.5 & 0.12 \pm 0.01 \\ & 4.7-7.5 & 0.27 \pm 0.07\end{array}$

*Inferred from timing of acoustic emissions.

${ }^{+}$No premonitory compression. 

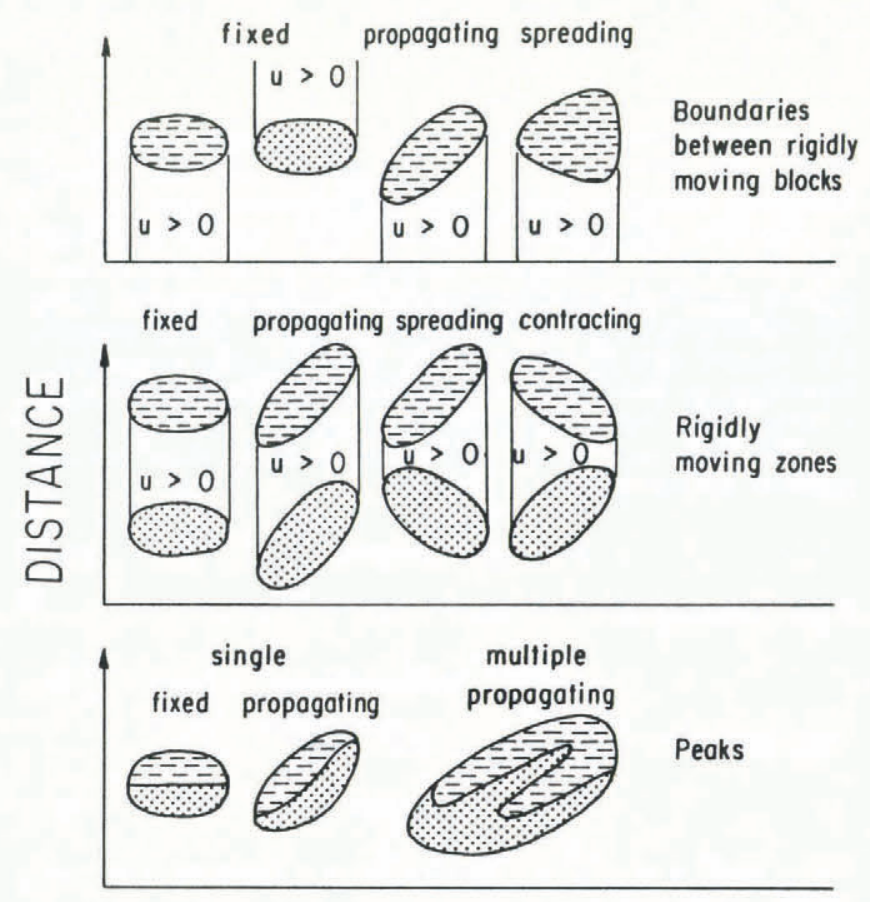

\section{TIME}

Fig. 8. Schematic representation of space-time patterns of strain anomaly corresponding to simple velocity-anomaly patterns.

The boundaries between zones of extensile and compressive strain-rate anomaly shown in Figure 7 were drawn in the simplest possible way using the concepts in Figure 8 and the implied interpretation in terms of an associated velocityanomaly pattern. The net strains $e_{\text {total }}$ listed in Table II help to localize the maximum accumulated displacement in a mini-surge, net strains being extensile above it and compressive below it.

Together, these considerations lead to the following qualitative description of each of the mini-surges for which strain measurements are available:

$79 / 1,29$ June. Based on premonitory compression at $7.5 \mathrm{~km}$ and extension at $5.5 \mathrm{~km}$, it appears as if there was a gradual speed-up of the whole region around $6.6 \mathrm{~km} \quad \approx 5 \mathrm{~km}$ to $7 \mathrm{~km}$ ) starting about $8 \mathrm{~h}$ before localized initiation of a propagating double-wave pattern at around $6 \frac{1}{2} \mathrm{~km}$. (This suggests the mini-surge did not initiate in the tributary, but was associated with the gradual acceleration of the $5 \mathrm{~km}$ to $7 \mathrm{~km}$ reach.) Net strains extensile above $6.6 \mathrm{~km}$ and compressive at $7.5 \mathrm{~km}$ indicate maximum displacement between $6.6 \mathrm{~km}$ and $7.5 \mathrm{~km}$.

$79 / 3,11$ July and 79/4, 17 July. These mini-surges appeared similar. Based on premonitory compression at $5.5 \mathrm{~km}$, it appears as if there was a gradual speed-up above $5.5 \mathrm{~km}$ starting about $1 \mathrm{~d}$ before initiation of a propagating double-wave pattern from above $5.5 \mathrm{~km}$ to below $7.5 \mathrm{~km}$. All net strains are compressive, indicating maximum displacement above $5.5 \mathrm{~km}$.

$80 / 2,1$ July. All strain anomalies are rather weak and the patterns seem rather simple; extension at $5.5 \mathrm{~km}$, compression at $7.0 \mathrm{~km}$ and $8.3 \mathrm{~km}$. It appears that this event originated between $5.5 \mathrm{~km}$ and $7.0 \mathrm{~km}$ and spread up-glacier and down-glacier rather than showing a distinct down-glacier propagation.

$80 / 3,5-6$ July. Distinct anomalies at $8.3 \mathrm{~km}$ and $9.6 \mathrm{~km}$ show propagation past these places. Weak extension at $4.3 \mathrm{~km}$ and an indistinct pattern showing primarily extension at $5.5 \mathrm{~km}$ suggests initiation near $5.5 \mathrm{~km}$ or below. Some initial compression before onset of extension in the tributary suggests the possibility of initiation in the tributary.
$80 / 4,8-9$ July. Distinct patterns at $4.3 \mathrm{~km}$ and $5.5 \mathrm{~km}$ show propagation past these places, and net compression there shows maximum displacement above $4.3 \mathrm{~km}$. A seismic peak at $8.6 \mathrm{~km}$ indicates propagation to that point, but lack of distinct strains at $9.6 \mathrm{~km}$ indicates termination before there (although there may have been small strains obscured by diurnal instrumental noise from melting). Mini-surges $80 / 3$ and $80 / 4$ may have been somewhat complimentary, the earlier passage of $80 / 3$ having desensitized the lower part of the observation zone to propagation of $80 / 4$ from higher up.

$80 / 5,14-15$ July. Increased compression rate at $5.5 \mathrm{~km}$ and decreased compression at $4.3 \mathrm{~km}$ starting late on 12 July indicate a premonitory acceleration of the glacier $2 \mathrm{~d}$ before the event. The opposite changes mid-day on 15 July suggest a termination of the anomalous motion then. A weak double-wave pattern at $5.5 \mathrm{~km}$ suggests initiation of a propagating phase above there on 15 July. Strain and seismicity at lower sites show propagation to $8.6 \mathrm{~km}$ or below.

$81 / 3,25-26$ June and $81 / 4,1-2$ July. Because of limited spatial sampling, the description of these two mini-surges is uncertain. Based on only two strain meters, they seem to have propagated with low speed from above $4.7 \mathrm{~km}$ to below $7.5 \mathrm{~km}$. The anomalous straining lasted longer than in the mini-surges of 1979 and 1980.

$81 / 5 a$ and $5 b, 13-15 \mathrm{July}$. On $13 \mathrm{July}$, extension at $4.7 \mathrm{~km}$ and compression at $7.5 \mathrm{~km}$ indicate speed-up of the intervening zone. Based on seismic activity, the zone of anomalous motion may have originated locally between $5 \mathrm{~km}$ and $7 \mathrm{~km}$ and then gradually spread out, both up- and down-glacier. The upward-spreading extensional edge then apparently triggered a mini-surge starting on 14 July from above $4 \mathrm{~km}$ and propagating downward. It did not propagate strongly past $7.5 \mathrm{~km}$ where strain was highly compressive. The prior activity $(81 / 5 a)$ on 13 July in this zone may have desensitized it to propagation of a second pulse $(81 / 5 b)$.

\section{Quantitative estimate of velocity anomaly}

The velocity anomaly $\dot{u}(x, t)$ could be estimated if the spatial and temporal distributions of $\dot{e}(x, t)$ were well-known. The available sampling of $\dot{e}(x, t)$ is not adequate to do this rigorously, but progress is possible with some reasonable assumptions. For the purposes of discussion, we examine two distinct cases: (1) the velocity anomaly propagates longitudinally at a definite speed $w$ and fixed shape $f(x-w t)$, and (2) the velocity anomaly is fixed in space with a certain shape $g(x)$. In each case, we allow the amplitude of the spatial pattern to vary with time $t$. The first case should be reasonably applicable in those circumstances where propagation of a definite strainanomaly pattern is clearly apparent. The second may be applicable in the several mini-surges where no propagation was apparent. We consider them in turn.

In the case of propagation of a fixed shape we have

$$
\dot{u}(x, t)=a(t) f(x-w t) .
$$

From Equation (2)

$$
\dot{e}(x, t)=a(t) f^{\prime}(x-w t) .
$$

Differentiation of Equation (5) with respect to $t$ gives

$$
\frac{\partial \dot{u}(x, t)}{\partial t}=w a(t) f^{\prime}(x-w t)+a^{\prime}(t) f(x-w t) .
$$

Combination of Equations (5), (6), and (7) gives

$$
\frac{\partial \dot{u}(x, t)}{\partial t}-\propto \dot{u}(x, t)=-w \dot{e}(x, t)
$$

where $\alpha=a^{\prime}(t) / a(t)$ is the fractional rate of amplitude change. We now consider a certain fixed location $x$ (a 
strain-meter site), and we choose $t=0$ to be that time when the leading edge of the propagating wave reaches $x$. We also assume that $\alpha$ is constant during the time interval the wave is affecting $x$. With these specifications, the solution to Equation (8) using standard techniques is

$$
\dot{u}(x, t)=-w \exp (\alpha t) \int_{0}^{t} \dot{e}(x, \tau) \exp (-\alpha \tau) \mathrm{d} \tau .
$$

Integration by parts allows this to be expressed in terms of the accumulated strain anomaly defined by Equation (3) with the result

$$
\dot{u}(x, t)=-w e(x, t)-\alpha w \exp (\alpha t) \int_{0}^{t} e(x, \tau) \exp (-\alpha \tau) \mathrm{d} \tau .
$$

The second term on the right can be interpreted by integration of Equation (8) with respect to time and the definitions of accumulated strain and displacement anomalies from Equations (3) and (4) to find

$$
\dot{u}(x, t)-\propto u(x, t)=-w e(x, t) .
$$

Comparison of Equations (10) and (9b) shows

$$
u(x, t)=-w \exp (\alpha t) \int_{0}^{t} e(x, \tau) \exp (-\alpha \tau) \mathrm{d} \tau .
$$

The validity of Equation (11) is also verified by differentiating it with respect to time to find Equation ( $9 \mathrm{~b}$ ). It expresses the accumulated displacement in terms of strain Also, if we consider Equation (10) for $t=T$ sufficiently large that the wave has passed and $\dot{u}(x, T) \approx 0$, we find

$$
\alpha=\frac{w e(x, T)}{u(x, T)} .
$$

Therefore, if the wave velocity $w$ and the total displacement $u(x, T)$ are known, $\alpha$ can be estimated and the velocity $\dot{u}(x, t)$ can be found from $e(x, t)$ using Equation (9b).

In the circumstance that the wave has fixed amplitude as well as shape $(a=$ constant, $\alpha=0)$, then $u(x, t)=$ $w e(x, t)$, which is immediately clear from Equation (8). Thus, the velocity anomaly is proportional to the strain anomaly. The second term on the right of Equation (9b) represents a correction to this simple interpretation of strain in terms of velocity, when wave amplitude is changing.

We now turn to the case of a spatially fixed velocity anomaly of the form

$$
\dot{u}(x, t)=b(t) g(x) .
$$

From Equation (2)

$$
\dot{e}(x, t)=b(t) g^{\prime}(x) .
$$

This, combined with Equation (13), gives

$$
\dot{u}(x, t)=\mathrm{B}(x) \dot{e}(x, t)
$$

where $B(x)=g(x) / g^{\prime}(x)$. Integration of Equation (15) with respect to time gives

$$
u(x, t)=\beta(x) e(x, t) .
$$

Therefore, if the accumulated displacement anomaly is known over some interval $t=T$, and if $e(x, t)$ is not zero, the parameter $\beta$ can be determined from Equation (16), and Equation (15) can be used to find the short time-scale variation of velocity anomaly. In this case velocity anomaly is proportional to strain-rate.

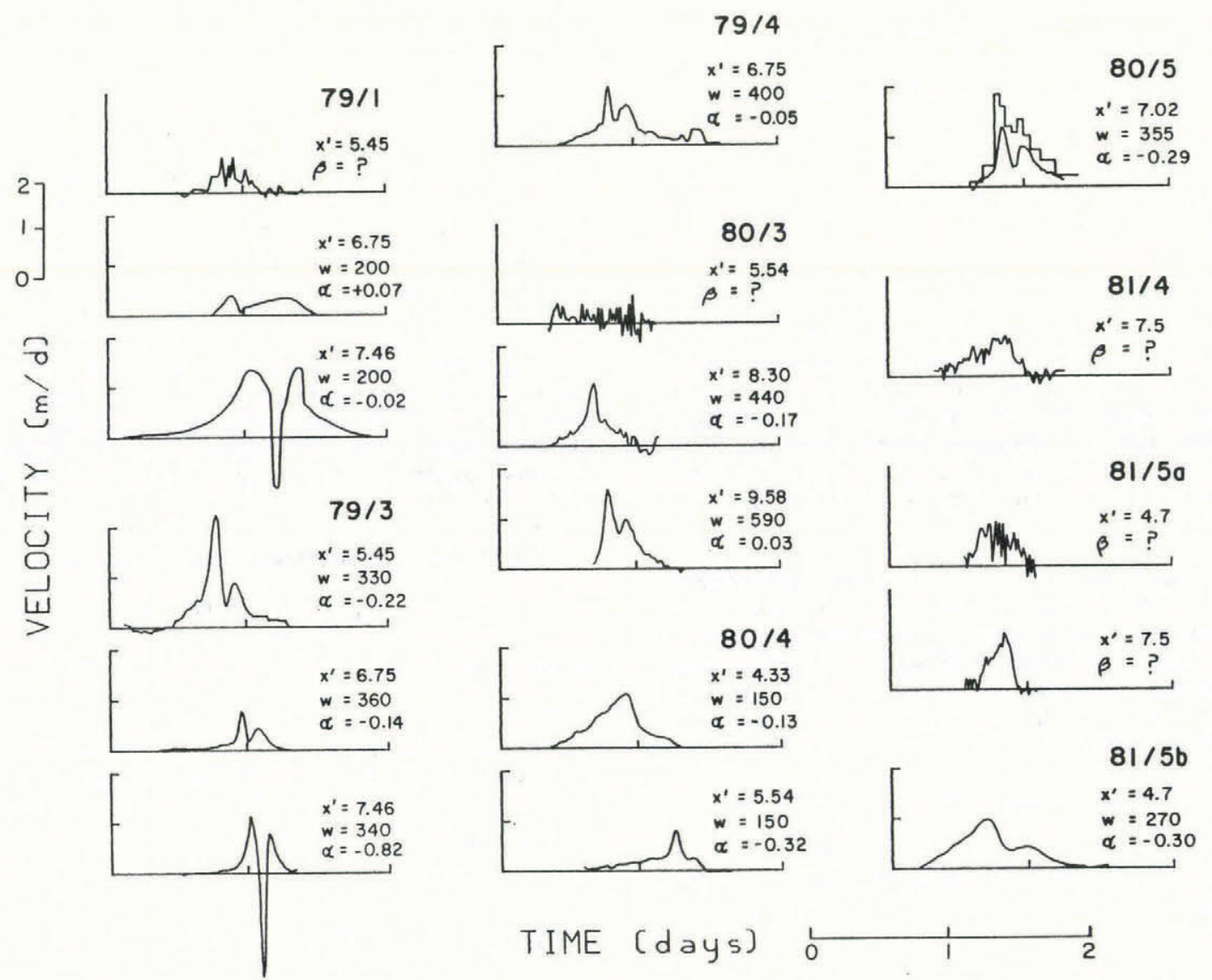

Fig. 9. Velocity anomaly inferred from Equation (9b), indicated by parameters $w$ and $\alpha$, or from Equation (15), indicated by parameter B. Choice of parameters is explained in the text. Ticks are absent from the velocity axis where data for scaling the inferred velocity anomaly are unavailable. Direct measurements of velocity in mini-surge $80 / 5$ are shown for comparison, as discussed in text. 
Figure 9 shows the time variation of velocity anomaly deduced indirectly from the strain variation in mini-surges using Equations (9b) or (15), depending on whether Equations (5) or (13) seemed more realistic, based on the space-time evolution of the strain anomaly shown in Figure 7.

For certain mini-surges and locations, the first case represented by Equations (5) and (9b) seems very reasonable because of well-defined propagation and a reasonably constant shape. In these cases, with one exception, $w$ was chosen from Table III and $\alpha$ was chosen to minimize the ratio $T|\dot{u}(x, T)| / u(x, T)$ calculated by dividing Equation (9b) by Equation (11) each evaluated at $T$ after the mini-surge had passed. This ratio is independent of $w$ and gives the ratio of the velocity anomaly at the end of the mini-surge to the average during the mini-surge. This procedure was followed since $\dot{u}(x, T)$ and $u(x, T)$ were unknown at most of the strain-meter sites. For mini-surge $80 / 5$ at $7.02 \mathrm{~km}$, values of $\dot{u}(x, T)$ and a local wave velocity $w$ were known from the measurements of Kamb and Engelhardt (in press) at a nearby site, and these were used to determine $\alpha$.

In a few other mini-surges and locations, assumptions corresponding to Equation (13) seem more reasonable. These locations are in the beginning and starting zones. The total displacement anomaly $u(x, T)$ was not measured at any of these locations, so that parameter $B$ could not be estimated. Therefore, Equation (16) shows at most the trend of velocity variations and results are plotted with unscaled velocity axes. Also, because velocity anomaly is proportional to strain-rate, noise in the estimate shows up strongly as a result of differentiation of the digitized strain record.

In a number of cases no estimates of velocity were attempted at all, either because the strain-rate anomaly was small in comparison to accuracy or because neither set of assumptions for Equations (5) or (13) seemed even approximately valid.

Naturally, these indirect velocity estimates must be viewed cautiously, since neither set of assumptions will be perfectly correct and the information needed to choose the relevant parameters is not complete. Nevertheless, the structures of the deduced velocity patterns are probably correct. In particular, the double velocity peak deduced in the cases of well-defined velocity-wave propagation is probably a real feature.

\section{COMPARISON OF WIRE-METER STRAIN WITH OTHER OBSERVATIONS}

\section{Relative timing of velocity, water level, and strain variations}

Kamb and Engelhardt (in press) have measured short time-scale velocity variations directly by standard surveying during the mini-surges of 1980 and 1981. The timings of velocity peaks at measured locations are shown in Figure 7 . The transitions from relative compression to relative extension coincide approximately with velocity peaks, but a close examination reveals that of ten the velocity peaks precede the strain transitions by about $\frac{1}{2} \mathrm{~h}$. Velocity peaks occur when $\partial \dot{u}(x, t) / \partial t=0$. For propagating anomalies described by Equation (5), Equation (8) shows that this happens when

$$
\dot{e}(x, t)=\frac{\alpha}{w} \dot{u}(x, t) .
$$

The available comparisons of velocity and strain timing occur in circumstances where total strain anomaly is compressive, indicating decreasing anomaly amplitude with down-glacier distance $(\alpha<0)$, so that Equation (17) is satisfied when $\dot{e}(x, t)$ is still compressive and before the transition to extension. If the time shifts involved are independent of distance, then the propagation speeds of the strain transition listed in Table III will approximate the propagation speeds of velocity peaks. In the zones of initiation and stopping of a mini-surge, Equations (5) and (9b) are not applicable, and one can expect that velocity peaks will more closely coincide with strain-rate peaks rather than transitions (zeros). Therefore, outside of zones of distinct propagation the space-time trajectories of strain transitions do not portray the trajectories of velocity peaks.

Water level measured in bore holes by Kamb and Engelhardt (in press) during the 1979 and 1980 mini-surges estimate basal water pressure. They show glacier-motion velocity peaks coincide closely with peaks in water level during the 1980 mini-surges in the vicinity of $6 \mathrm{~km}$ to $7 \mathrm{~km}$ from the glacier head where their surveying measurements were concentrated. The timing of these water-level peaks is shown for comparison with strain features in Figure 7. In 1979, time resolution of survey measurements was not adequate to establish the timing of velocity peaks, but this timing can be inferred from the strain pattern. The comparisons for the 1979 mini-surges show that velocity and water-level peaks also coincided in the $6 \mathrm{~km}$ to $7 \mathrm{~km}$ vicinity, where measurements were made.

Water-level fluctuations measured at $8.1 \mathrm{~km}$ during the 1980 mini-surges displayed peaks that were shifted relative to the strain-anomaly transitions. The firmest example of this is mini-surge $80 / 5$ when water level at $8.1 \mathrm{~km}$ peaked $2 \mathrm{~h}$ before the strain transition. Conceivably, this could represent an example of a large shift of velocity peak relative to water-level peak in this zone of the glacier. More likely, it represents a large shift of velocity peak relative to the strain transition. This seems very possible, since strain at $8.1 \mathrm{~km}$ was mainly compressive with only a weak extensile phase (Table II), suggesting that the minisurge was dying out there.

\section{Comparison of directly measured and inferred velocity variations}

A detailed comparison is possible only for mini-surge $80 / 5$. The strain meter at $7.0 \mathrm{~km}$ was positioned in a zone through which the strain anomaly was propagating (Figs 5 and 7 ), and Equation (9b) would provide a reasonable basis for computing velocity. Nearby, at $6.5 \mathrm{~km}$, velocity was measured directly by $\mathrm{Kamb}$ and Engelhardt (in press). Figure 9 shows their results compared to estimates from the strain record using $w$ and $\alpha$, chosen to match $\dot{u}(x, T)=$ $0.22 \mathrm{~m} \mathrm{~d}^{-1}$ and $w=355 \mathrm{~m} \mathrm{~h}^{-1}$, as measured by Kamb and Engelhardt. The agreement is reasonable. The shift in time is consistent with the down-glacier propagation over the approximately $500 \mathrm{~m}$ longitudinal spacing of the sites. The difference in amplitude is compatible with the down-glacier decrease in amplitude implied by the value of $a$. Two peaks in velocity are shown in each case. In opposition to these points of agreement, the first velocity peak is too narrow and the second one too broad when strain-estimated velocity is compared to directly measured velocity. Also, the negative value of $a$ inferred seems too large in magnitude, since the mini-surge propagated a substantial distance below this location without dramatic attenuation. Therefore, the amplitude of the velocity deduced from the strain seems too small. Presumably, the reason for these discrepancies would be that the propagating velocity pulse does not have a fixed shape and wave velocity and/or the amplitude does not vary smoothly along the glacier length.

Although it is not possible to compare directly measured and inferred velocity for other sites and minisurges in detail, the typical level of velocity anomaly predicted by the strain-anomaly pattern is less than expected based on net displacements measured at other locations, which is the same tendency noted above. Therefore, the strain pattern cannot be trusted for an accurate velocity measurement, but it can be used to discern some of the detailed structure of velocity variation with time.

\section{EVOLUTION OF MINI-SURGE BEHAVIOR}

\section{Progression within one summer season}

The progression of mini-surges within a single summer showed two trends: (1) early mini-surges tended to initiate lower than later ones (Fig. 7); (2) at $6 \mathrm{~km}$ to $7 \mathrm{~km}$ the intensity of successive mini-surges increased (Table II). Certain other features, although variable, did not seem to show consistent trends. Examples are: mini-surge propagation speed (Table III) and the interval of anomalous straining (Fig. 7).

\section{Year-to-year changes in mini-surge behavior}

Based on the observed strain and strain-rate anomalies, the intensity of mini-surges decreased from year to year in the interval 1979 to 1981 (Table II). In particular, the early mini-surges of 1980 and 1981 were weak and showed no or 
slow propagation. The dramatic double-wave patterns found consistently in 1979 (Fig. 3) were found again in 1980 and 1981 , but they appear not to have been nearly so pronounced or widespread. In these last two years the observations at $7.0 \mathrm{~km}$ during mini-surge $80 / 5$ represent the strongest observed example of this behavior (Figs 5 and 10).

Because of differences in sensitivity and location of sensors, it is difficult to establish relative intensity of mini-surges from the seismometers. Qualitatively, the impression from the recorded seismic data is consistent with the above-inferred, year-to-year trend. Also, audible seismic activity of the 1979 mini-surges was very dramatic and considerably more noticeable than that in 1980 or 1981 . In addition, fine-scale shattering of the glacier surface found in 1979 in the reach $6 \mathrm{~km}$ to $7 \mathrm{~km}$ (paper in preparation by N. Humphrey) was not apparent in 1980 and 1981.

The trend of decreasing strain-rate and strain anomalies in mini-surges seems somewhat counter to the progressive year-to-year increase in speed in this part of the glacier (paper in preparation by C.F. Raymond and W.D. Harrison) and the approaching surge which started in January 1982. On the other hand, the difference between secular summer velocity and mini-surge velocity peaks was not increasing from year to year (Harrison and others, 1986; Kamb and Engelhardt, in press), which is consistent with a lack of high strain-rates in spite of the high speeds.

\section{VARIATION OF VELOCITY AT THE BED}

Assuming the rheology of Variegated Glacier ice is constant or at most slowly varying in time, it is clear that the surface-velocity and strain-rate variations of mini-surges arise from changes in basal-slip velocity. If the changes in basal-slip velocity are constant over large areas, then change in surface and bed velocities are nearly equal. In the case of these propagating mini-surges, the changes vary in space (vertical lines in Fig. 9) on scales that suggest that bedvelocity variations may be attenuated toward the upper surface by longitudinal and lateral stress gradients. Furthermore, the strain-rates vary substantially on time-scales (horizontal lines in Fig. 7) short enough that transient, nonsteady creep of the ice is expected (Duval, 1976) and transfer of basal variations to the surface may involve both elastic and viscous strain contributions.

These questions are addressed in detail, based on various assumed linear viscous, visco-elastic, and elastic rheologies, and simplified geometry by Balise and Raymond (1985) and M.J. Balise (paper in preparation). If the material is assumed to be entirely incompressible (both viscously and elastically), the results are independent of shear viscosity or elastic modulus, or any visco-elastic combination. If the material is assumed to be viscously incompressible but elastically compressible, this is no longer true but the basic features of the results are not importantly modified. These analyses show that a very broad peak in basal velocity produces a similar peak at the surface. If the width of the basal velocity peak is less than about ten depths, the amplitude of the surface peak is reduced in comparison to the bed. If the width of the basal velocity peak is less than about two depths, it produces a double peak in surface velocity separated by several depths and phased such that the minimum between them lies over the basal peak. This latter, somewhat surprising result cautions us that some of the detailed structure of the surface-velocity variation on spatial scales shorter than $3 \mathrm{~km}$ to $4 \mathrm{~km}$ could be an indirect consequence of ice-straining effects, that peaks in the surface velocity do not necessarily coincide with peaks in the bed velocity, with possible shifts up to about a depth, and that the strain at the surface does not represent well the average over depth.

Based on these concepts, we infer that a mini-surge is associated with an asymmetric peak in basal velocity with the same basic shape of rapid rise and slow decay seen at the surface. On the other hand, a double peak at the surface may indicate a single, very narrow, high transient peak in sliding velocity during the beginning of a mini-surge.

\section{DESCRIPTIVE MODEL OF MINI-SURGE MECHANISM}

Iken and others (1983) have observed patterns of velocity variation on Unteraargletscher, Switzerland, which have some resemblance to the mini-surges of Variegated Glacier. Based on the observed correlation of horizontal velocity with surface uplift, theoretical models (Iken, 1981) and earlier concepts about glacier sliding (Lliboutry, 1968), they hypothesized that the increased speed they observed was caused by the action of water in basal cavities. They also inferred that the pressure of the water was of principal importance through its effect on the opening or closing rate of basal cavities and that the amount of basal water present was of secondary importance.

The combined observations of speed and basal water pressure of Kamb and Engelhardt (in press) establish directly that basal water is the cause of the fast mini-surge speeds and that propagation occurs by passage of a hydraulic wave in the basal water system. The narrow, high peak in sliding velocity indicated by the strain measurements would be consistent with a transient enhancement of sliding caused by the rapid opening of basal cavities in response to the very rapidly increasing water pressure upon arrival of the hydraulic wave. Therefore, this would support the conclusion that formation of basal cavities and, in particular, the transients involved play a principal role in the mini-surge mechanism. The measurement of anomalous surface uplift during mini-surges by Kamb and Engelhardt (in press) gives a seemingly more direct indication of the opening of cavities and even a measure of their average thickness change, but this is also severely complicated by vertical straining of the ice according to Balise and Raymond (1985). However, the combined effects seem to affirm the importance of basal cavities.

Similar to the concepts expressed by Iken and others (1983), we believe the mini-surges occur at the beginning of the melt season because water input from surface melt is faster than can be transmitted by the constricted hydraulic system which has contracted over the previous winter. This leads to back-up of water in the system, water storage, and increased water pressure at the bed. A mini-surge originates locally where the water pressure first reaches a level high enough to cause substantial separation at the bed with the combined consequence of increased basal slip velocity and effective hydraulic transmissivity. The lower edge of this zone propagates as a front under the influence of the large, longitudinal gradient in effective hydraulic transmissivity so induced. The hydraulic wave speed is also affected by a storage factor which relates water storage to pressure in the basal system. The propagation of the hydraulic wave allows some of the excess water to be drained, the basal water pressure to drop, the basal separation to close, and the mini-surge to retard. If the basal hydraulic transmissivity has not increased sufficiently to accommodate the water input, another mini-surge initiates with timing depending on the water input balance, the needed pressure rise, and the storage factor. as the melt season progresses and hte basal hydraulic system opens by thermal and creep processes (Röthlisberger, 1972; Nye, 1976), the mini-surge initiation is less likely but it still might occur after times of exceptionally high water input.

\section{REFERENCES}

Balise, M.J., and Raymond, C.F. 1985. Transfer of basal sliding variations to the surface of a linearly viscous glacier. Journal of Glaciology, Vol. 31, No. 109, p. 308-18.

Bindschadler, R., and others. 1977. Geometry and dynamics of a surge-type glacier, by R. Bindschadler, W.D. Harrison, C.F. Raymond, and R. Crosson. Journal of Glaciology, Vol. 18, No. 79, p. 181-94.

Duval, P. 1976. Lois du fluage transitoire ou permanent de la glace polycristalline pour divers états de contrainte. Annales de Géophysique, Tom. 32, No. 4, p. 335-50. 
Evans, K., and others. 1978. Recording wire strainmeters on the Barnes Ice Cap, Baffin Island, Canada, by K. Evans, D.J. Goodman, and G. Holdsworth. Journal of Glaciology, Vol. 20 , No. 83 , p. 409-23.

Flotron, A. 1973. Photogrammetrische Messung von Gletscherbewegungen mit automatischer Kamera. Vermessung, Photogrammetrie und Kulturtechnik, Jahrg. 71, Ht. 1-73, p. 15-17.

Harrison, W.D., and others. 1986. Short period motion events on Variegated Glacier as observed by automatic photography and seismic methods, by W.D. Harrison, C.F. Raymond, and P. MacKeith. Annals of Glaciology, Vol. 8 , p. $82-89$.

Humphrey, N., and others. 1986. Discharges of turbid water during mini-surges of Variegated Glacier, Alaska, U.S.A., by N. Humphrey, C.F. Raymond, and W.D. Harrison. Journal of Glaciology, Vol. 32, No. 111, p. 178-91.

Iken, A. 1978. Variations of surface velocities of some Alpine glaciers measured at intervals of a few hours. Comparison with Arctic glaciers. Zeitschrift für Gletscherkunde und Glazialgeologie, Bd. 13, Ht. 1/2, 1977, p. 23-35.

Iken, A. 1981. The effect of the subglacial water pressure on the sliding velocity of a glacier in an idealized numerical model. Journal of Glaciology, Vol. 27, No. 97, p. 407-21.
Iken, A., and others. 1983. The uplift of Unteraargletscher at the beginning of the melt season - a consequence of water storage at the bed? By A. Iken, H. Röthlisberger, A Flotron, and W. Haeberli. Journal of Glaciology, Vol. 29, No. 101 , p. 28-47.

Kamb, W.B., and Engelhardt, H.F. In press. Waves of accelerated motion in a glacier approaching surge: the mini-surges of Variegated Glacier, Alaska, U.S.A. Journal of Glaciology.

Kamb, B., and others. 1985. Glacier surge mechanism: 1982-1983 surge of Variegated Glacier, Alaska, by B. Kamb [and 7 others]. Science, Vol. 227, No. 4686, p. 469-79.

Lliboutry, L. 1968. General theory of subglacial cavitation and sliding of temperate glaciers. Journal of Glaciology, Vol. 7 , No. 49 , p. 21-58.

Nye, J.F. 1976. Water flow in glaciers: jokulhlaups, tunnels and veins. Journal of Glaciology, Vol. 17, No. 76, p. 181-207.

Rogers, G. Unpublished. The study of a microearthquake swarm. [M.S. thesis, University of Hawaii, 1972.]

Rothlisberger, H. 1972. Water pressure in intra- and subglacial channels. Journal of Glaciology, Vol. 11, No. 62 , p. 177-203.

VanWormer, D., and Berg, E. 1973. Seismic evidence for glacier motion. Journal of Glaciology, Vol. 12, No. 65, p. 259-65. 